\title{
Monodispersed LiFePO @C Core-Shell Nanoparticles Anchored on 3D Carbon Cloth for High-Rate Performance Binder-Free Lithium Ion Battery Cathode
}

\author{
Boqiao Li, ${ }^{1}$ Wei Zhao, ${ }^{2}$ Chen Zhang, ${ }^{1}$ Zhe Yang, ${ }^{1}$ Fei Dang, ${ }^{1}$ YiLun Liu, ${ }^{1}$ Feng Jin $\mathbb{D},{ }^{1}$ \\ and Xi Chen ${ }_{(i D}^{2,3}$ \\ ${ }^{1}$ International Center for Applied Mechanics, State Key Laboratory for Strength and Vibration of Mechanical Structures, \\ School of Aerospace, Xi'an Jiaotong University, Xi'an 710049, China \\ ${ }^{2}$ School of Chemical Engineering, Northwest University, Xi'an 710069, China \\ ${ }^{3}$ Earth Engineering Center, Center for Advanced Materials for Energy and Environment, Department of Earth and \\ Environmental Engineering, Columbia University, New York, NY 10027, USA
}

Correspondence should be addressed to Feng Jin; jinzhao@mail.xjtu.edu.cn and Xi Chen; xichen863@hotmail.com

Received 16 January 2020; Accepted 11 March 2020; Published 30 April 2020

Academic Editor: Thathan Premkumar

Copyright ( $\odot 2020$ Boqiao Li et al. This is an open access article distributed under the Creative Commons Attribution License, which permits unrestricted use, distribution, and reproduction in any medium, provided the original work is properly cited.

Owing to high safety, low cost, nontoxicity, and environment-friendly features, $\mathrm{LiFePO}_{4}$ that is served as the lithium ion battery cathode has attracted much attention. In this paper, a novel 3D LiFePO$@ @ C$ core-shell configuration anchored on carbon cloth is synthesized by a facile impregnation sol-gel approach. Through the binder-free structure, the active materials can be directly combined with the current collector to avoid the falling of active materials and achieve the high-efficiency lithium ion and electron transfer. The traditional slurry-casting technique is applicable for pasting $\mathrm{LiFePO}_{4} @ \mathrm{C}$ powders onto the 2D aluminum foil current collector (LFP-Al). By contrast, LFP-CC exhibits a reversible specific capacity of $140 \mathrm{mAh} \cdot \mathrm{g}^{-1}$ and $93.3 \mathrm{mAh} \cdot \mathrm{g}^{-1}$ at $1 \mathrm{C}$ and 10C, respectively. After 500 cycles, no obvious capacity decay can be observed at 10C while keeping the coulombic efficiency above $98 \%$. Because of its excellent capacity, high-rate performance, stable electrochemical performance, and good flexibility, this material has great potentials of developing the next-generation high-rate performance lithium ion battery and preparing the binder-free flexible cathode.

\section{Introduction}

Lithium ion batteries (LIB), as the most important electrochemistry energy storage (EES), have attracted great attention from many researchers in the world and are widely applied in the portable electronics and electric vehicle industries due to their long cycle life, high energy density, and portability $[1,2]$. However, their comprehensive performances are still limited by each component of the battery, especially for cathode. Consequently, cost, safety, cycle life, and battery capacity may be seriously impacted [3]. Lithium iron phosphate $\left(\mathrm{LiFePO}_{4}\right)$ that was taken as the cathode material had been firstly reported by Padhi and his coworkers in 1997 [4]. Compared with many lithium compounds, $\mathrm{LiFePO}_{4}$ has lots of advantages, such as relatively high theoretical energy density $(170 \mathrm{mAh} / \mathrm{g})$, high safety, low cost, nontoxicity, and environmentfriendly features $[5,6]$. However, its overall capacity cannot be completely released because of its low electricity and ionic conductivity [7]. Fortunately, various strategies have been employed to overcome the abovementioned limitations, such as size reduction [8], conductive surface coating [9], lattice engineering [10], and surface engineering [11, 12]. In particular, carbon surface coating is proved to be quite effective for improving the performances of the $\mathrm{LiFePO}_{4}$ cathode [13]. Xu et al. [14] prepared the monodis- 
persed $\mathrm{LiFePO}_{4} @ \mathrm{C}$ core-shell nanostructure cathode material synthesized by a solvothermal route with ethylene glycol (EG), and the reaction medium has a high-rate capacity and excellent cycle performance. Chen et al. [15] synthesized the ultrathin $\mathrm{LiFePO}_{4} / \mathrm{C}$ nanoflakes using an evaporated selfassembly method, exhibiting the excellent specific capacity and stable capacity retention.

For the different carbon surface-coating methods, the citric acid-assist sol-gel method has its huge advantages of controlling the morphology and particle size. In the sol-gel process, the effective nanoscale carbon layers are formed in situ, which can not only control the grain growth of $\mathrm{LiFePO}_{4}$ particles but also offer a fast pathway for ion and electron transmission [16]. However, the single nanoscale design of $\mathrm{LiFePO}_{4}$ still has some limitations because the comprehensive performance of the battery may be influenced by the whole electrode morphology and configuration. Traditionally, slurry casting with binders has some intrinsic shortcomings of electrochemical performance during the electrode manufacturing process [17], for instance, bulk particle agglomeration, weakly contact between active materials and current collector, and increased internal resistance from binders. Fortunately, the relevant drawbacks can be effectively avoided by the rising binder-free flexible electrode. With regard to such novel electrode configuration, the active materials are embedded into 3D flexible current collector so as to achieve well dispersion and strong combination between active materials and current collector. Without any polymeric binder and conductive additive in this kind of electrodes, the loading mass of active materials is apparently improved for better cycle stability and specific capacity. However, there is still a lack of low-cost and high-efficiency methods to prepare the binder-free flexible cathode. The existing synthesis techniques like hydrothermal [18] and electrodeposition [19] have the intrinsic drawbacks of low reproducibility, high cost, and uncontrollable reaction process. In order to further develop the flexible cathodes with potential application value, it is necessary to explore a new method to prepare the binder-free flexible cathodes.

In this paper, a facile method is proposed to prepare an integral composite electrode by taking $\mathrm{LiFePO}_{4}$ as active materials and carbon cloth as the current collector. Based on the inherent characteristics of the citric acid in situ sol-gel method, $\mathrm{LiFePO}_{4} @ \mathrm{C}$ nanoparticles are fixed on the surface of carbon cloth by in situ encapsulation effect and citric acid carbonization. This novel electrode structure has exhibited 3D morphology of monodispersed LiFe$\mathrm{PO}_{4} @ \mathrm{C}$ core-shell nanostructure that is coated on the single carbon fiber of carbon cloth. Meanwhile, a contrast experiment is performed for this integral electrode and traditional $\mathrm{Al}$ foil slurry-casting electrode using the same active materials of $\mathrm{LiFePO}_{4} @ \mathrm{C}$ nanoparticles. Research results show that this novel electrode exhibits an excellent low rate performance $(140 \mathrm{mAh} / \mathrm{g}$ at $1 \mathrm{C})$ and high-rate performance ( $93.3 \mathrm{mAh} \cdot \mathrm{g}^{-1}$ at $\left.10 \mathrm{C}\right)$. Noticeably, the extremely stable cycle performance can be exhibited under high rate (no obvious capacity decay is observed after 500 cycles under 10C) by comparison to $\mathrm{Al}$ foil electrode with only $69.75 \%$ capacity retention under 10C.

\section{Experimental Study}

\subsection{Material Preparation}

2.1.1. Activated Carbon Cloth. The pristine carbon cloth purchased from CeTech Co. (Type WOS1009) was activated by a typical method. A clean carbon cloth was cut into slices of $1 \mathrm{~cm} \times 1 \mathrm{~cm}$ and put into a three-necked flask with nitric acid. Then, the mixture was heated at $100^{\circ} \mathrm{C}$ for $24 \mathrm{~h}$ under oil bath condition. Finally, the activated carbon cloth was flushed with deionized water and ethanol for three times and dried under vacuum conditions.

2.1.2. LiFePO $@$ @C/Carbon Cloth Composite Electrode. Figure 1 clearly displays that $\mathrm{LiFePO}_{4} @ \mathrm{C} /$ carbon cloth composite electrode is prepared by a simple impregnation sol-gel method, with which the novel 3D $\mathrm{LiFePO}_{4} / \mathrm{C}$ core-shell nanostructure is established. First of all, $\mathrm{LiFePO}_{4}$ precursor solution was prepared by mixing citric acid monohydrate $(0.2 \mathrm{~mol} / \mathrm{L}), \mathrm{LiNO}_{3}(0.1 \mathrm{~mol} / \mathrm{L}), \mathrm{FeSO}_{4} \cdot 7 \mathrm{H}_{2} \mathrm{O}(0.1 \mathrm{~mol} / \mathrm{L})$, and $\mathrm{NH}_{4} \mathrm{H}_{2} \mathrm{PO}_{4}(0.1 \mathrm{~mol} / \mathrm{L})$ in the beaker. Next, the mixture was stirred at $80^{\circ} \mathrm{C}$ until the sol was shaped. And then, the carbon cloth was soaked in the sol solution for $1 \mathrm{~h}$ and dried for $10 \mathrm{~h}$ in the drying oven so as to form the gel layer on the surface of the carbon cloth. Finally, the dried carbon cloth was put into the muffle furnace, sintered at $700^{\circ} \mathrm{C}$ with $5^{\circ} \mathrm{C} / \mathrm{min}$ for $10 \mathrm{~h}$ under argon atmosphere and naturally cooled down to the room temperature.

2.1.3. Pristine $\mathrm{LiFePO}_{4} @ \mathrm{C}$ Nanoparticle. In the contrast experiment, the pristine $\mathrm{LiFePO}_{4} @ \mathrm{C}$ nanoparticles without carbon cloth were prepared as the current collector. Except for soaked carbon cloth, the preparation process was the same as that in Section 2.1.2. The sol solution was dried for $10 \mathrm{~h}$ in the drying oven to shape the xerogel, then sintered at $700^{\circ} \mathrm{C}$ with $5^{\circ} \mathrm{C} / \mathrm{min}$ for $10 \mathrm{~h}$ under argon atmosphere; eventually, $\mathrm{LiFePO}_{4} @ \mathrm{C}$ powder was obtained.

2.2. Characterization of Materials. X-ray diffraction (XRD) patterns were collected from a Bruker D8 ADVANCE diffractometer with $\mathrm{Cu} K \alpha$ radiation $(\lambda=0.15418 \mathrm{~nm})$; then, the diffraction data was received for $2 \theta$ angles from $10^{\circ}$ to $70^{\circ}$. The morphology and microstructure were featured by a scanning electron microscope (SEM, Zeiss GeminiSEM 500 ) with an acceleration voltage of $15 \mathrm{kV}$ and a transmission electron microscope (TEM, JEOL JEM-F200) with an acceleration voltage of $200 \mathrm{kV}$. The surface element and structure were characterized by X-ray photoelectron spectroscopy (XPS, Thermo Fisher ESCALAB), covering the scan range from $0 \mathrm{eV}$ to $1200 \mathrm{eV}$.

2.3. Electrochemical Measurement. In the samples, the electrochemistry performances were assessed with coin cells (CR2032) and assembled in a glove box under the oxygen and water concentrations of about $1 \mathrm{ppm}$. The negative electrode was made up of Li metal and the liquid electrolyte with $1 \mathrm{M} \mathrm{LiPF}_{6}$ in the solvent mixture of ethylene carbonate (EC) and dimethyl carbonate (DMC) $(1: 1)$; meanwhile, a microporous polypropylene film (Celgard 2400) was used as the separator. Two kinds of samples were used as the working 


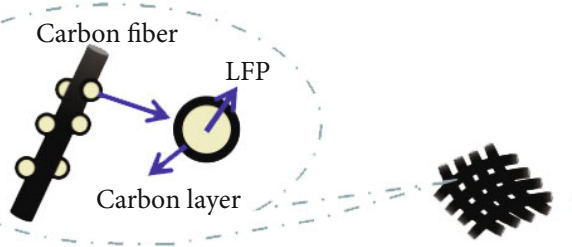

Calcination

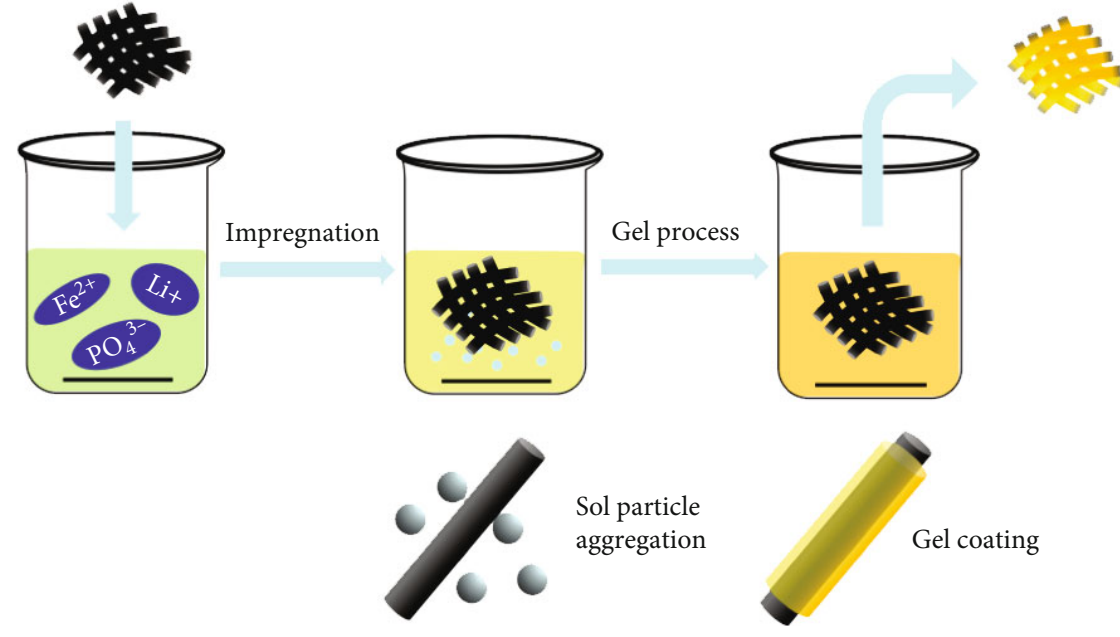

FIGURE 1: Schematic illustration of the preparation process and the microstructure of $\mathrm{LiFePO}_{4} @ \mathrm{C} /$ carbon cloth electrode.

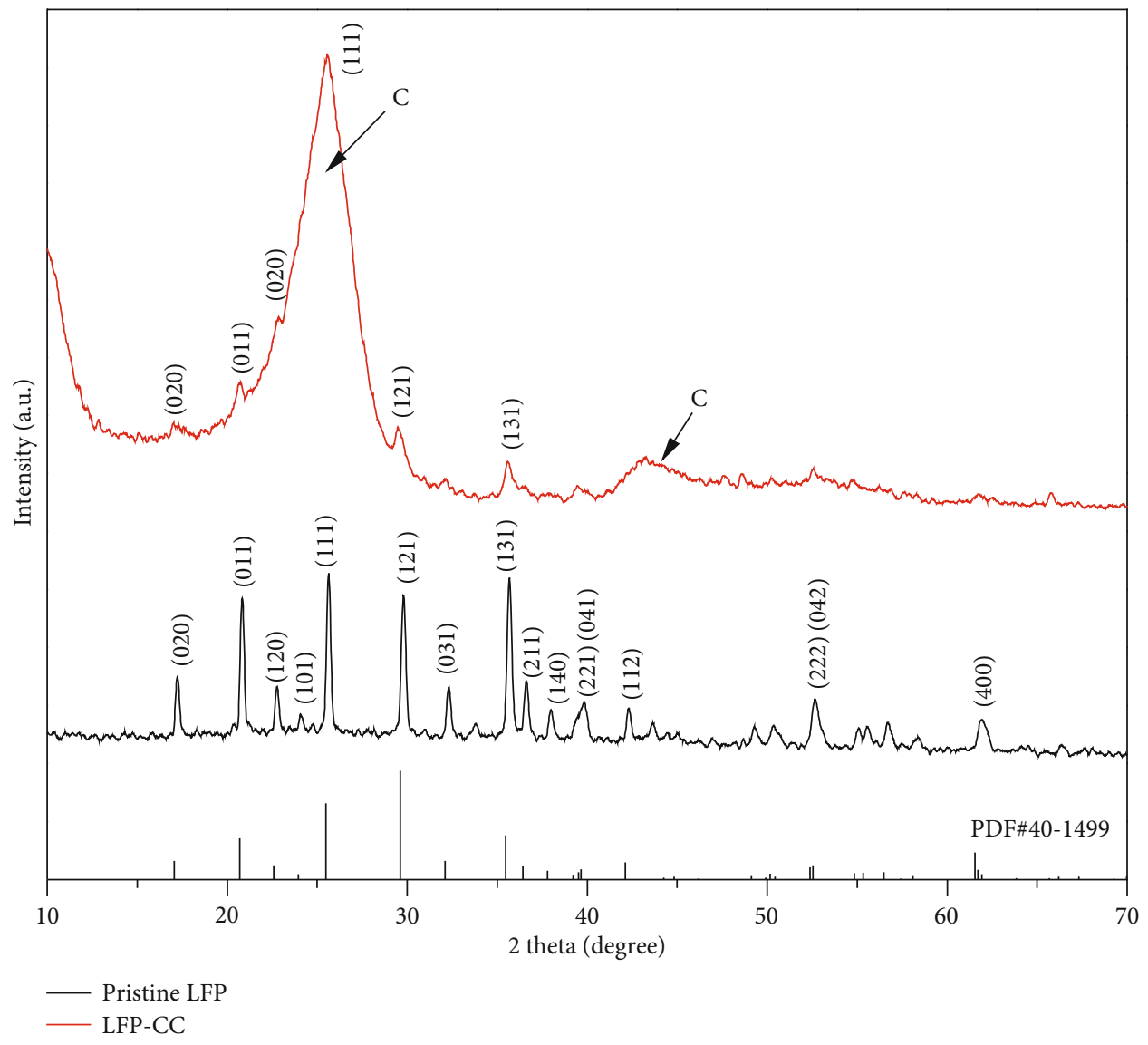

FIGURE 2: XRD patterns of pristine LFP and LFP-CC. 


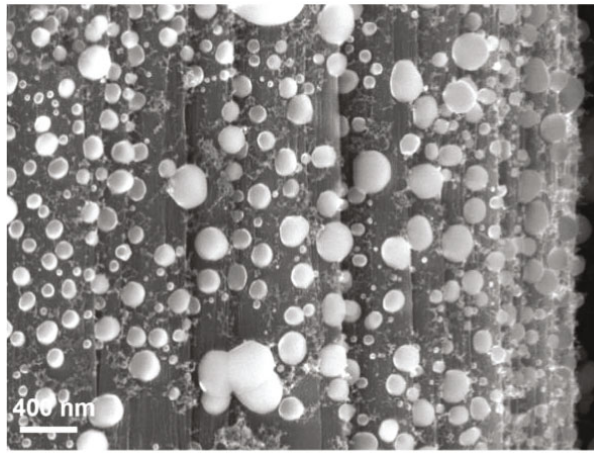

(a)

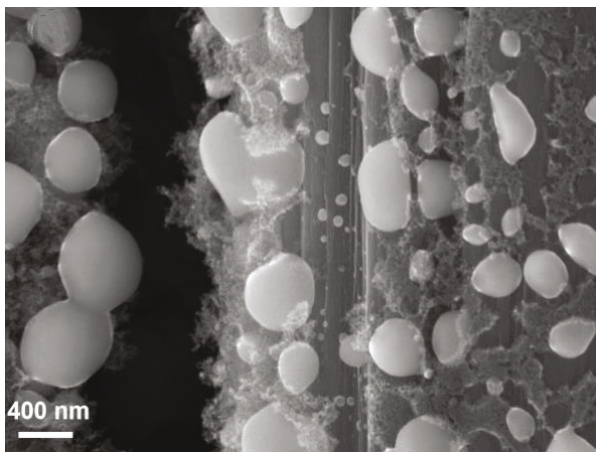

(c)

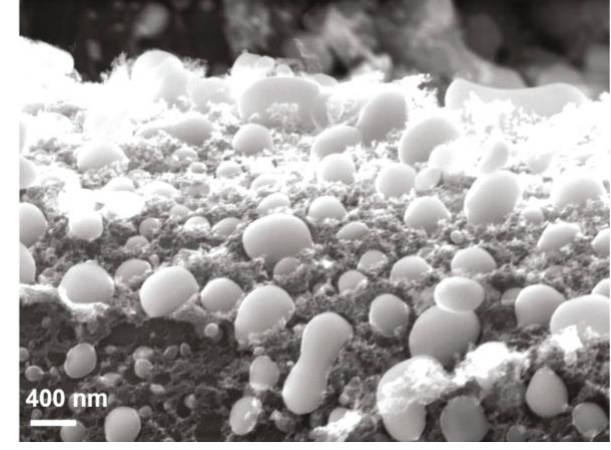

(b)

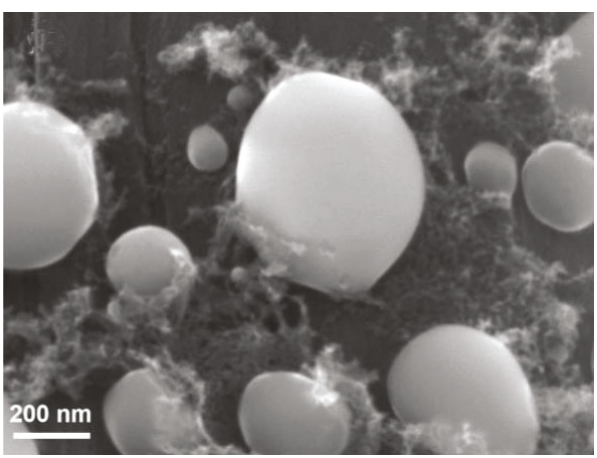

(d)

FIGURE 3: SEM morphology structures of LFP-CC (a-d) based on different image magnifications and profiles.

electrode. In sample 1, LiFePO $@$ @C/carbon cloth composite electrode was chosen with the loading mass of the active material about $2.5 \mathrm{mg} / \mathrm{cm}^{2}$. The so-called LFP-CC could be directly used as the working electrode. And the mixture of the active material $\left(\mathrm{LiFePO}_{4} @ \mathrm{C}\right.$ powder $\left.80 \mathrm{wt} \%\right)$, carbon black (Super P, 10 wt\%), and polyvinylidene fluoride (PVDF10wt\%) was dispersed in N-methyl-2-pyrrolidone (NMP). The received slurry was pasted onto an $\mathrm{Al}$ foil and dried at $80^{\circ} \mathrm{C}$ overnight under vacuum condition. The loading mass of the active material was about $2.3 \mathrm{mg} / \mathrm{cm}^{2}$. In sample 2 , the so-called LFP-Al could be taken as the working electrode. Besides, LANHE CT2001A system was used to measure the battery performance in the voltage range of $2.5 \mathrm{~V}-4.2 \mathrm{~V}$ (vs. $\mathrm{Li}^{+} / \mathrm{Li}$ ) with different rates at room temperature. Cyclic voltammetry (CV) and electrochemical impedance spectroscopy (EIS) were conducted on a CHI-660E electrochemical workstation. CV was implemented in the potential range of $2.5 \mathrm{~V}$ $4.2 \mathrm{~V}$ (vs. $\mathrm{Li}^{+} / \mathrm{Li}$ ) at a scan range of $0.5 \mathrm{mV} \cdot \mathrm{s}^{-1}$ while EIS was carried out in the frequency range from $0.1 \mathrm{~Hz}$ to $100 \mathrm{kHz}$.

\section{Results and Discussion}

As shown in Figure 2, the diffraction peaks of two samples are well indexed for the olivine structure $\mathrm{LiFePO}_{4}(\mathrm{PDF}$ No. 40-1499). In particular, three strong lines of (111), (121), and (131) crystal planes at $25.5^{\circ}, 29.6^{\circ}$, and $35.5^{\circ}$, respectively, were obviously observed, indicating high purity and crystallinity of prepared $\mathrm{LiFePO}_{4}$. Compared with the pristine $\mathrm{LiFePO}_{4}$ sample, LFP-CC had the relatively weak characteristic peaks of $\mathrm{LiFePO}_{4}$ because the strong peaks of the carbon cloth substrate were set around $26^{\circ}$ and $43^{\circ}$ [20]. However, no other impurity phase was found in XRD patterns of the LFP-CC sample, indicating that $\mathrm{LiFePO}_{4}$ with an intact crystal structure was well coated onto the carbon cloth.

Figure 3 shows the $3 \mathrm{D}$ nanostructure of the $\mathrm{LiFePO}_{4} @ \mathrm{C} /-$ carbon cloth composite electrode. As shown in Figure 3(a), the monodispersed $\mathrm{LiFePO}_{4} @ \mathrm{C}$ nanoparticles were homogeneously anchored on the surface of the carbon cloth, offering the favorable contact between the active materials and current collector; every single particle was served as "microbattery" for the release of capacity. Figure 3(b) shows that the profile of this nanostructure could be observed in an intuitive manner. It was noteworthy that the bottom of the nanoparticles was wrapped by the carbon layer, which could attribute to the in situ citric acid carbonization effect, enhance the bonding strength, form the integrated flexible electrode, and promote the cycle life of the battery. Figure 3(c) exhibits the marginal morphology of the $\mathrm{LiFePO}_{4} @ \mathrm{C} /$ carbon cloth electrode. Also, the marginal positions were coated with $\mathrm{LiFePO}_{4} @ \mathrm{C}$ nanoparticles, indicating the effective mass loading around the carbon fibers. Figure $3(\mathrm{~d})$ displays the larger magnification of the images with the diameters of LiFe$\mathrm{PO}_{4} @ \mathrm{C}$ nanoparticles in the range of $100 \mathrm{~nm}$ to $400 \mathrm{~nm}$. Therefore, the nanoscale structures had effectively shortened the transmission path of lithium ions and electrons and improved the specific capacity and rate performance.

TEM investigation was performed to confirm the coreshell nanostructure of LFP-CC. The test samples were obtained from the ultrasound LFP-CC in ethanol solution. Figure 4(a) demonstrates that $\mathrm{LiFePO}_{4}$ nanoparticles are 


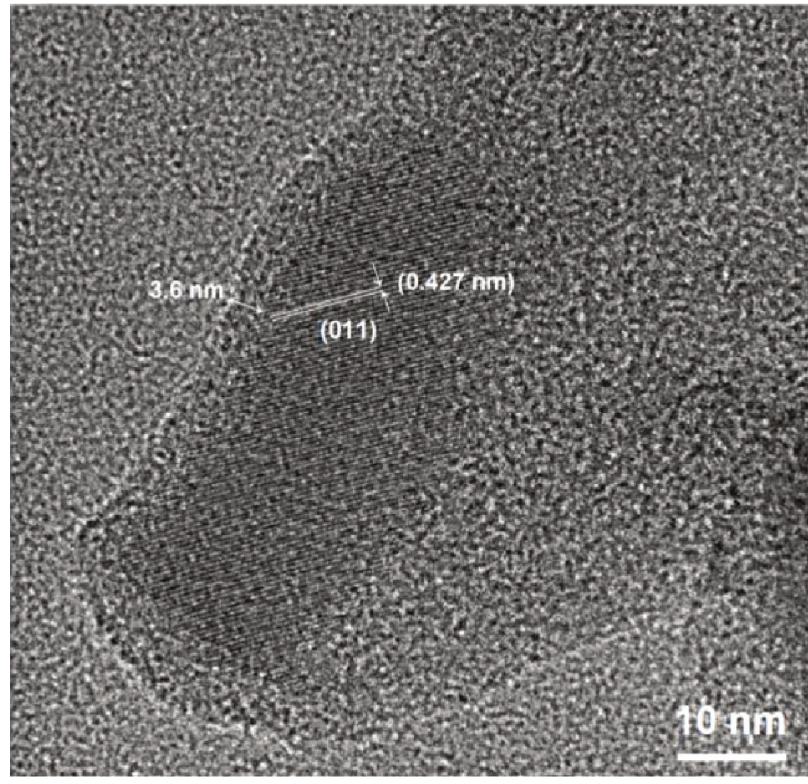

(a)

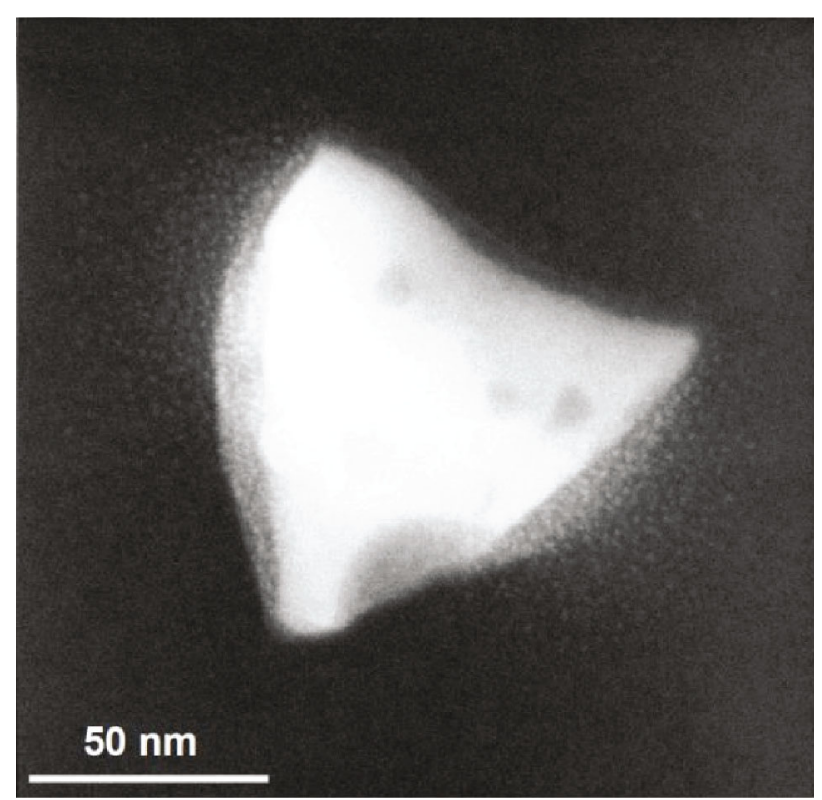

(b)

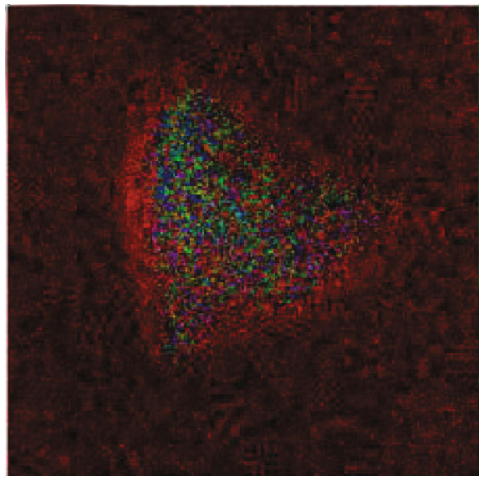

(c)

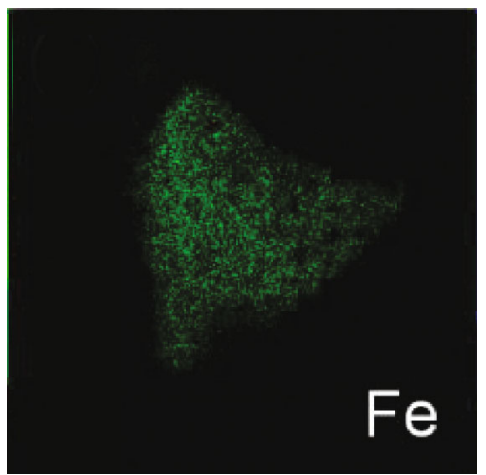

(d)

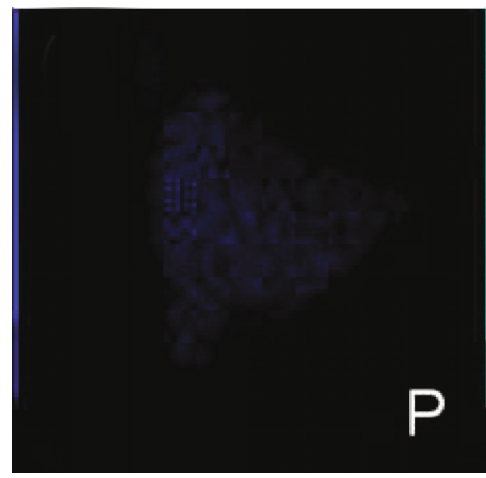

(e)

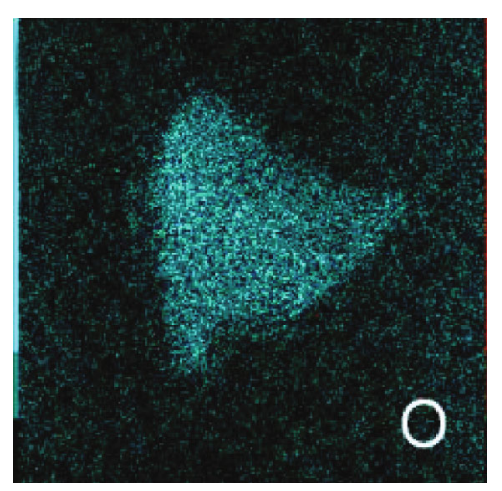

(f)

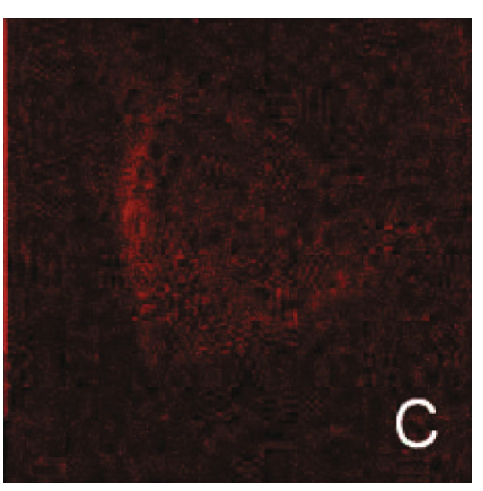

(g)

FIgure 4: TEM images (a, b) and elemental mapping images (c-g) of LFP-CC.

homogeneously wrapped by a thin carbon layer of about $3.6 \mathrm{~nm}$. Meanwhile, the interplanar crystal spacing of $\mathrm{LiFePO}_{4}$ can be observed clearly with the distance of $0.427 \mathrm{~nm}$, corresponding to the (011) crystal plane of olivine structure $\mathrm{LiFePO}_{4}$, which coincided with the XRD result. Also, TEM elemental mapping was conducted to analyze the core-shell nanostructure of single $\mathrm{LiFePO}_{4} @ \mathrm{C}$. In Figure 4(b), it was clearly observed that the diameter of a single $\mathrm{LiFePO}_{4} @ \mathrm{C}$ nanoparticle was about $50 \mathrm{~nm}$. As shown in Figures 4(c)$4(\mathrm{~g})$, the element distributions of $\mathrm{Fe}, \mathrm{P}, \mathrm{O}$, and $\mathrm{C}$ were characterized; that is, $\mathrm{Fe}, \mathrm{P}$, and $\mathrm{O}$ elements were located in the interior core, and $\mathrm{C}$ elements on the external edge. Results indicated that the $\mathrm{LiFePO}_{4}$-coated carbon layer of the core-shell nanostructure was successfully prepared.

$\mathrm{X}$-ray photoelectron spectroscopy (XPS) was applicable for analyzing the surface structure and element valence 
states. According to the XPS spectrum in Figure 5(a), Li, P, O, and $\mathrm{C}$ elements were observably present in the LFP-CC sample while the impurity elements $\mathrm{N}$ and $\mathrm{S}$ might be derived from the precursor materials of $\mathrm{LiNO}_{3}, \mathrm{FeSO}_{4} \cdot 7 \mathrm{H}_{2} \mathrm{O}$, and $\mathrm{NH}_{4} \mathrm{H}_{2} \mathrm{PO}_{4}$. From Figures 5(b)-5(e), the core-level spectra of $\mathrm{C} 1 \mathrm{~s}, \mathrm{Fe} 2 \mathrm{p}, \mathrm{O} 1 \mathrm{~s}$, and P 2p of LFP-CC were displayed, respectively. The fitted lines of Fe $2 p$ spectra showed two obvious characteristic peaks at $\mathrm{BE}$ of $710.3 \mathrm{eV}$ and $723.8 \mathrm{eV}$, which were assigned to Fe $2 \mathrm{p}_{3 / 2}$ and Fe $2 \mathrm{p}_{1 / 2}[21,22]$. The transition of metal ions with partially filled orbit was featured by two satellite peaks at higher $\mathrm{BE}$ of $713.8 \mathrm{eV}$ and $727.6 \mathrm{eV}$ because of the multiple splitting of Fe ion energy levels [23, 24]. The positions of main peaks and satellite peaks were well matched with the literature reports $[25,26]$, indicating the presence of $\mathrm{Fe}^{2+}$ ion in the LFP-CC sample. The fitted lines of $\mathrm{C} 1 \mathrm{~s}$ spectra demonstrated obvious $\mathrm{sp}^{2}$ and $\mathrm{sp}^{3}$ peaks at $284.6 \mathrm{eV}$ and $285.6 \mathrm{eV}$ [27], respectively, and the carbon layer was wrapped with $\mathrm{LiFePO}_{4}$ nanostructures in short-order $\mathrm{sp}^{2}$-coordinated and $\mathrm{sp}^{3}$-coordinated existing ways [28]. For the functional groups absorbed on the sample surface, two additional peaks were $\mathrm{C}-\mathrm{O}$ and $\mathrm{C}=\mathrm{O}$ at $287.9 \mathrm{eV}$ and $289.8 \mathrm{eV}$, respectively [29-32]. The fitted lines of O 1 s spectra showed the lattice oxygen at $531.0 \mathrm{eV}$; meanwhile, two additional peaks at $531.9 \mathrm{eV}$ and $533.0 \mathrm{eV}$ were also derived from $\mathrm{C}-\mathrm{O}$ and $\mathrm{C}=\mathrm{O}$, respectively, in the surface functional groups $[31,32]$. The fitted lines of $\mathrm{P}_{2 p}$ revealed the main peak at $133.8 \mathrm{eV}$, which was attributed to the structure of the $\mathrm{PO}_{4}{ }^{3-}$ group [21].

Figure 6(a) shows the initial cycle charge-discharge curve of LFP-Al and LFP-CC in the range of $2.5 \mathrm{~V}-4.2 \mathrm{~V}$ at $1 \mathrm{C}$. Both samples exhibited the stable charge-discharge plateau voltage at approximately $3.4 \mathrm{~V}$, indicating a two-phase redox reaction between $\mathrm{FePO}_{4}$ and $\mathrm{LiFePO}_{4}[33,34]$ as well as the reversible specific capacity of $140 \mathrm{mAh} \cdot \mathrm{g}^{-1}$. Compared with LFP-Al, the narrowed voltage gap of LFP-CC had been increased, suggesting that the polarization level in the LFP-CC sample was lower than that in the LFP-Al sample during the charge-discharge process. This phenomenon could be attributed to the carbon cloth current collector with a more effective $3 \mathrm{D}$ conductive network and monodispersed $\mathrm{LiFePO}_{4} @ \mathrm{C}$ nanoparticles. Figure 6(b) exhibits the charge-discharge curves of LFP-CC at the different $\mathrm{C}$ rates. The obvious characteristic plateau voltage was gradually disappeared with the increases of the $\mathrm{C}$ rate. In addition, the stable and symmetric curve could be obtained with a larger $\mathrm{C}$ rate, indicating that LFP-CC had excellent rate performance at a large $\mathrm{C}$ rate. In order to further confirm the rate performance of LFP-CC, a contrast experiment about the cycle rate performance between LFP-CC and LFP-Al was conducted, which is shown in Figure 6(c). With the increasing $\mathrm{C}$ rate, both of the samples revealed a slight capacity decay from $1 \mathrm{C}$ to $5 \mathrm{C}$, but the capacity was obviously decreased from $10 \mathrm{C}$ to $20 \mathrm{C}$. LFP-CC had released the discharge specific capacity of $93.3 \mathrm{mAh} \cdot \mathrm{g}^{-1}$ and $83.3 \mathrm{mAh} \cdot \mathrm{g}^{-1}$ at $10 \mathrm{C}$ and $20 \mathrm{C}$, respectively. In contrast, LFP-Al had a lower capacity of $68.4 \mathrm{mAh} \cdot \mathrm{g}^{-1}$ and $31.3 \mathrm{mAh} \cdot \mathrm{g}^{-1}$ at $10 \mathrm{C}$ and $20 \mathrm{C}$, respectively. Figure 6(d) shows the capacity retention and coulombic efficiency of LFP-CC and LFP-Al for 500 cycles at 10C. The LFP-CC sample exhibited the outstanding capacity retention and coulombic effi- ciency; after 500 cycles, no obvious capacity decay could be observed with coulombic efficiency above $98 \%$. For its inset, it was shown that the capacity decay of LFP-Al was obviously displayed with just $69.75 \%$ initial capacity after 500 cycles. Meanwhile, the coulombic efficiency (above 90\%) of LFP-Al was still lower than that of LFP-CC. Although the same active materials were taken in the experiment, the rate performance could be changed with the different current collectors. This was because of the difference between 3D binder-free integrated electrode and a typical 2D plate electrode with binders. In the binders, mechanical and electrochemical degradation could easily occur, especially for a large chargedischarge current [35].

Cyclic voltammetry (CV) and electrochemical impedance spectroscopy (EIS) were conducted to analyze the kinetics process of the electrode at the initial state and after 500 cycles at 10C. Figure 7(a) shows CV curves of LFP-CC. A pair of symmetric redox peaks with positive and negative directions could be observed, indicating the reversible deintercalation and intercalation process of lithium ion [36]. After 500 cycles, the curve was well matched with that of the fresh sample, indicating the excellent reversibility and stability of lithium ion insertion and extraction at a large rate. However, Figure 7(b) shows that in the LFP-Al sample, the potential gap was apparently changed from $0.68 \mathrm{~V}$ to $0.76 \mathrm{~V}$, which was larger than $0.3 \mathrm{~V}$ in the LFP-CC sample. Results suggested that LFP-CC had a better kinetics process and stability than LFP-Al. Nyquist plots of the electrochemical impedance spectroscopy (EIS) were shown in Figures 7(c) and 7(d). All of plots consisted of a partially overlapped semicircle in the high-frequency region and a slope in the low-frequency region. The semicircle corresponded to the charge transfer resistance $\left(R_{\mathrm{ct}}\right)$; the slope represented Warburg impedance $\left(Z_{\mathrm{w}}\right)$ associated with lithium ion diffusion in the bulk phase of the electrode [37]. Figure 7(c) shows the initial sample of LFP-Al and LFP-CC. The $R_{\mathrm{ct}}$ value in LFP-CC (57.4 $\Omega$ ) was significantly lower than that in LFP-Al (500.3 $\Omega$ ). That is to say that the interface reaction kinetics and charge transfer of LFP-CC were remarkably improved due to the introduction of carbon cloth current collector and nanostructure carbon-wrapped $\mathrm{LiFePO}_{4}$. As it is shown in Figure $7(\mathrm{~d})$, the $R_{\text {ct }}$ value in LFP-CC $(44.3 \Omega)$ was significantly lower than that in LFP-Al (271.1 $\Omega$ ) after 500 cycles, indicating a better reaction kinetics and charge transfer after a long cycle at a large $\mathrm{C}$ rate. Based on the slope in the Warburg region, the lithium ion diffusion coefficient $\left(D_{\mathrm{Li+}}\right)$ was calculated as follows [38]:

$$
D_{\mathrm{Li+}}=\frac{R^{2} T^{2}}{2 A^{2} n^{4} F^{4} C^{2} \sigma^{2}}
$$

where $R$ is the gas constant, $T$ is the absolute temperature, $A$ is the surface area of the electrode, $n$ is the number of transferred electrons per molecule during the electrochemical reaction process $\left(n=1\right.$ was obtained for $\left.\mathrm{LiFePO}_{4}\right), F$ is the Faraday constant, $C$ is the concentration of $\mathrm{Li}^{+}\left(7.69 \times 10^{-3}\right.$ $\mathrm{mol} \cdot \mathrm{cm}^{-3}$ was obtained for $\left.\mathrm{LiFePO}_{4}[36]\right)$, and $\sigma$ is the Warburg factor associated with $Z_{\text {re }}\left(Z_{\mathrm{re}} \propto \sigma \omega^{-1 / 2}\right)$. According to 
Journal of Nanomaterials

7

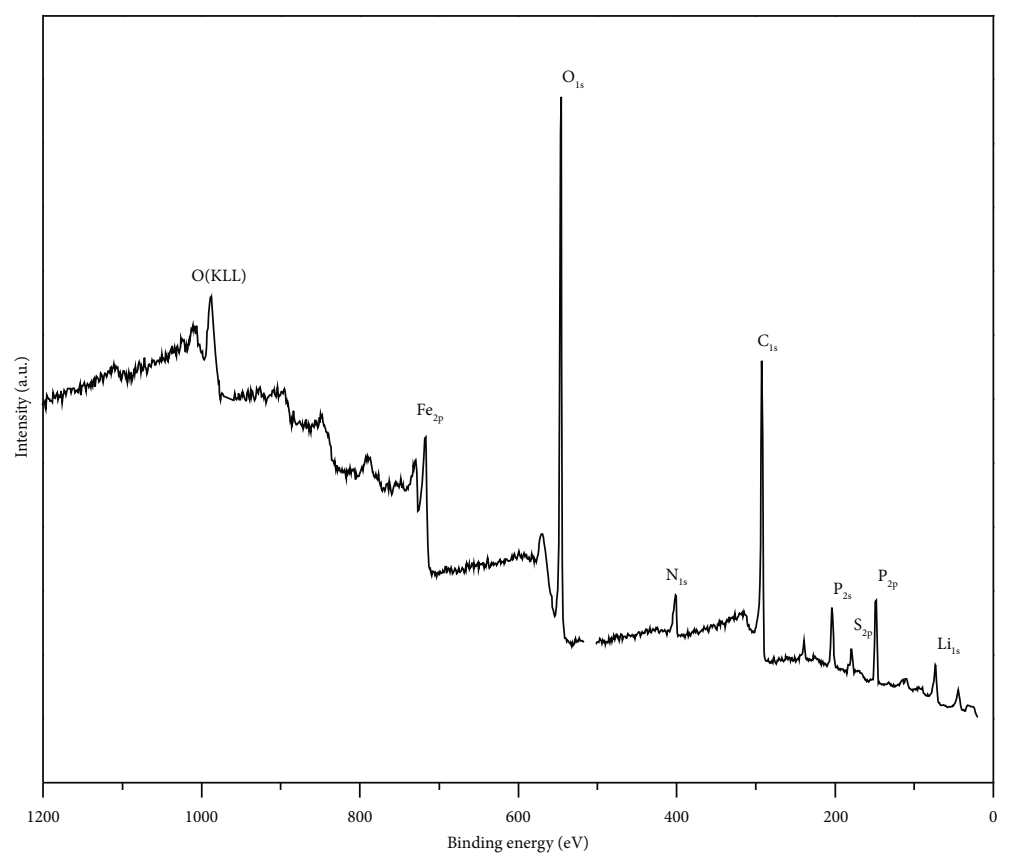

(a)

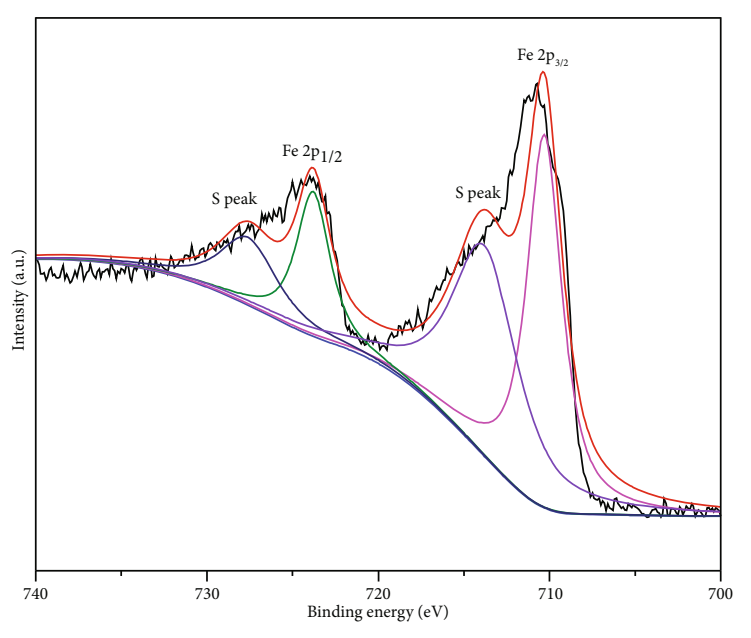

(b)

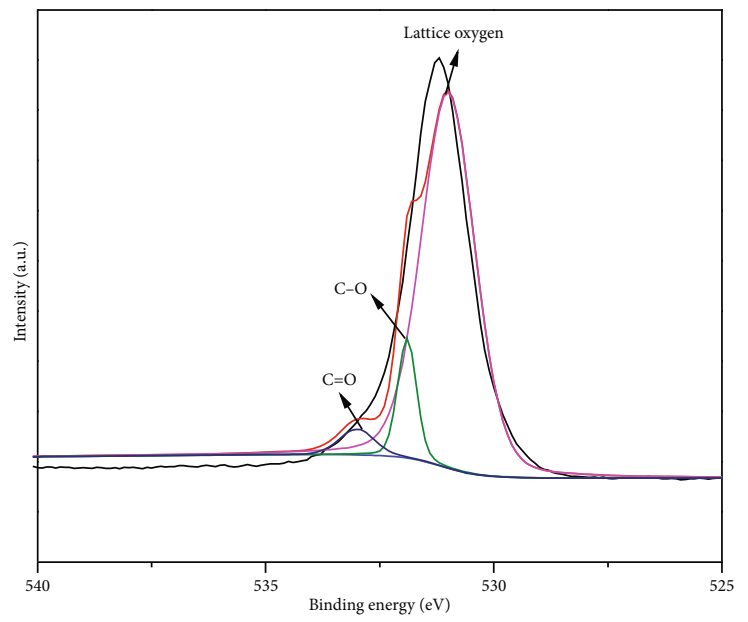

(d)

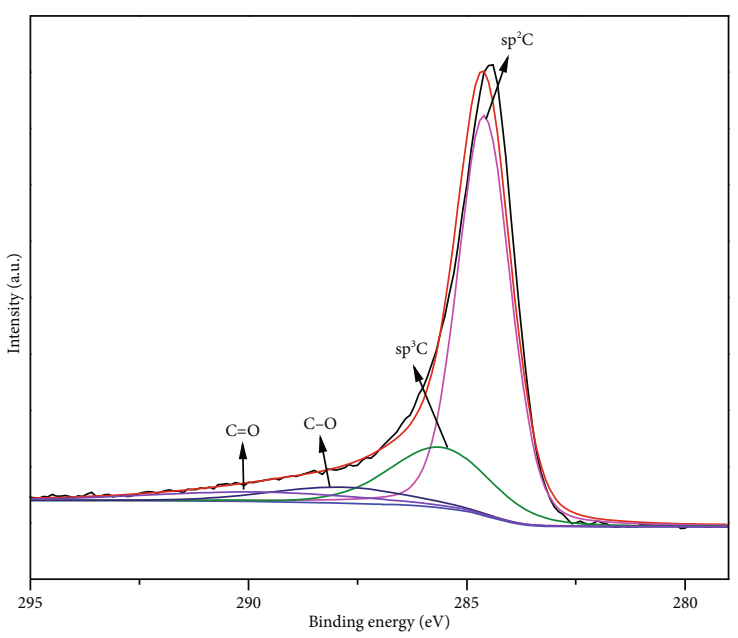

(c)

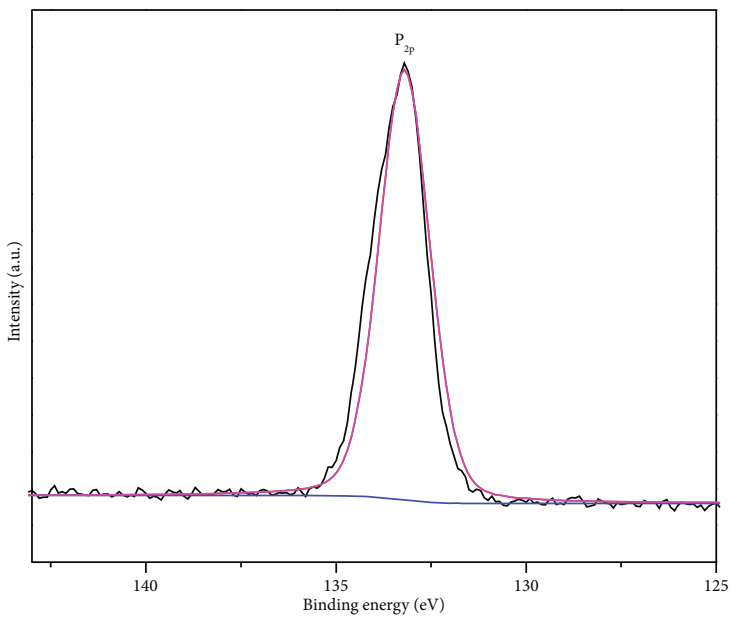

(e)

FIGURE 5: XPS spectra images of LFP-CC (a-e). 


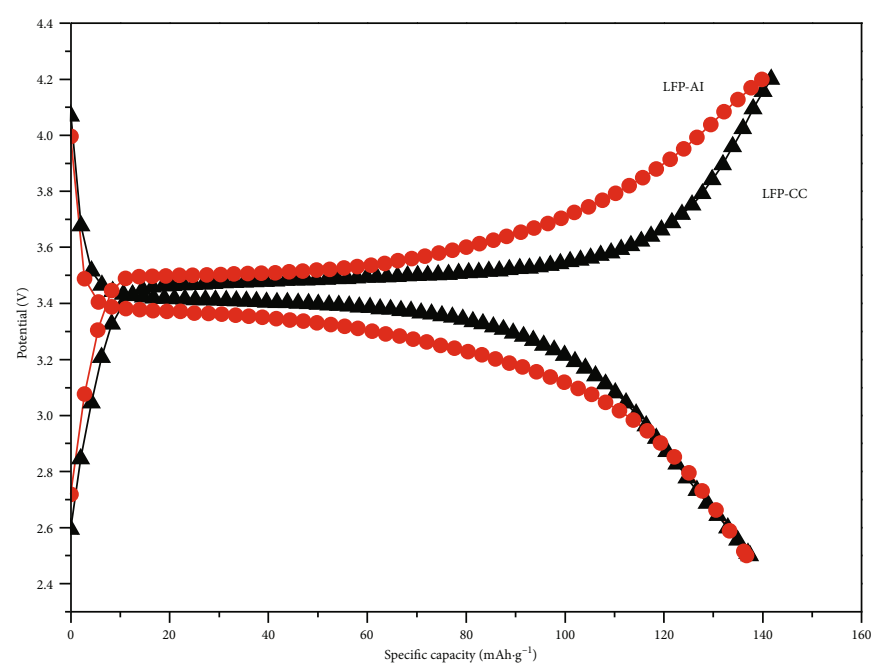

(a)

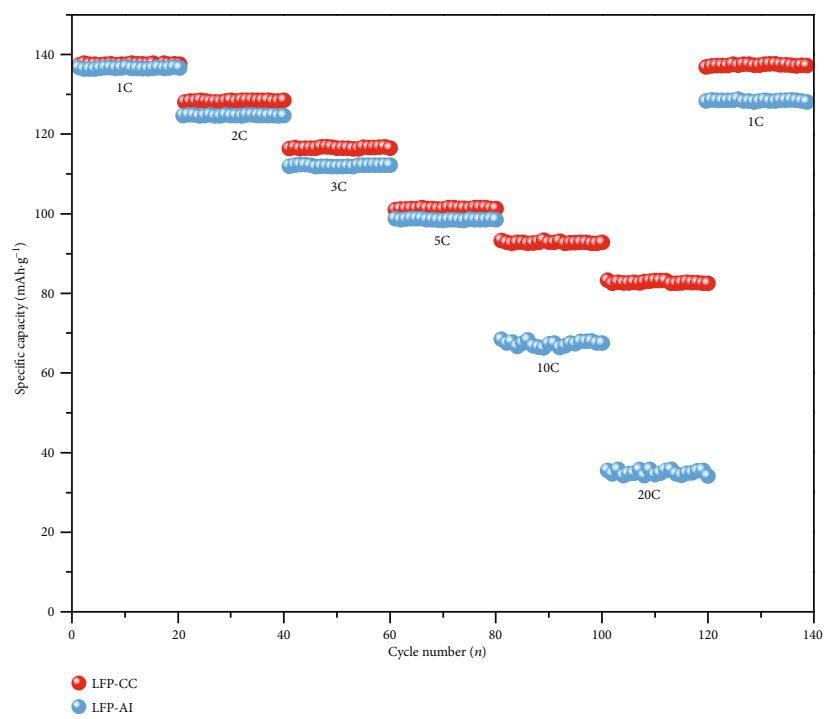

(c)

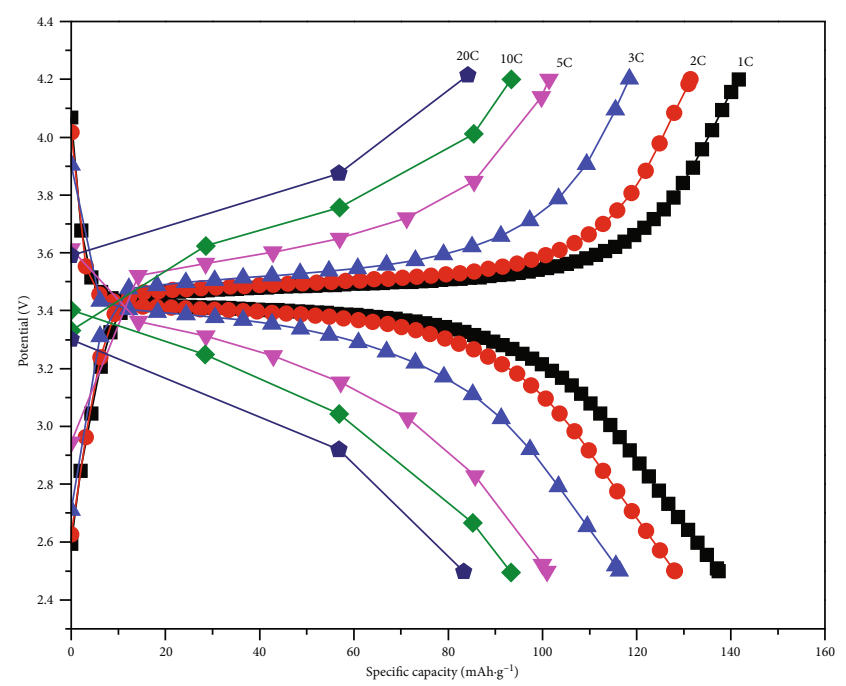

(b)

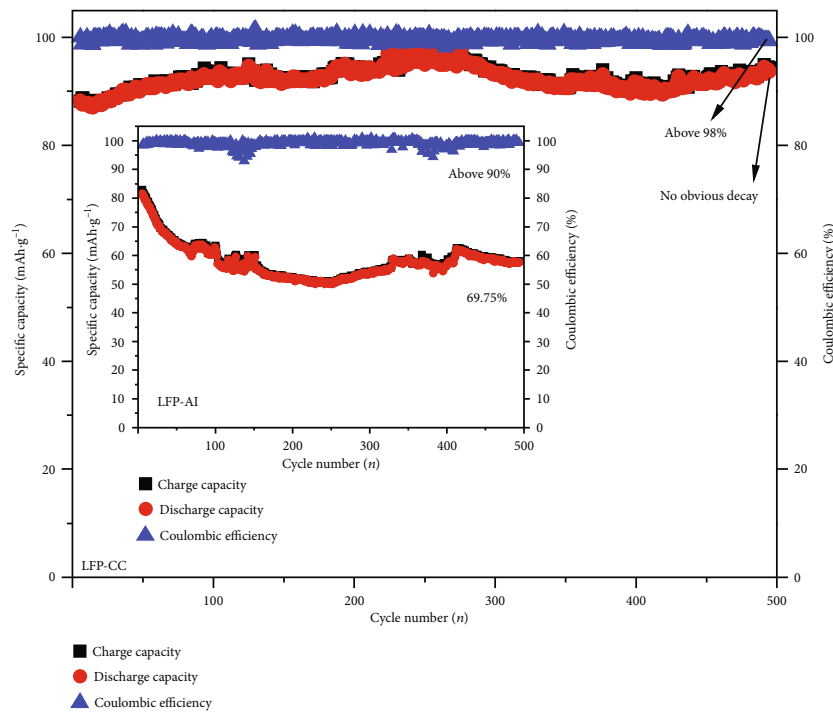

(d)

FIGURE 6: (a) Initial galvanostatic charge/discharge curve of LFP-Al and LFP-CC at 1C. (b) Galvanostatic charge/discharge curve of LFP-CC at different $\mathrm{C}$ rates. (c) Rate performance from 1C to 20C of LFP-Al and LFP-CC. (d) Capacity retention and coulombic efficiency of LFP-CC and LFP-Al (inset) at 10C during 500 cycles.

the linear fitted line between $Z_{\text {re }}$ and the inverse square root of angular frequency in the Warburg region, Warburg factor $\sigma$ was obtained through the following equation [38]:

$$
Z_{\mathrm{re}}=R_{\mathrm{e}}+R_{\mathrm{ct}}+\sigma \omega^{-1 / 2}
$$

where $R_{\mathrm{e}}$ is the resistance of the electrolyte and electrode.

The lithium ion diffusion coefficient $\left(D_{\mathrm{Li+}}\right)$ was calculated through Equations (1) and (2). The $D_{\mathrm{Li}+}$ values of initial LFP-Al, LFP-CC, 500th LFP-Al, and LFP-CC were obtained, namely, $3.745 \times 10^{-14}, 1.837 \times 10^{-13}, 1.114 \times$ $10^{-13}$, and $7.996 \times 10^{-13}$, respectively. Results showed that $D_{\mathrm{Li}+}$ in LFP-CC was 4.9 times and 7.2 times as high as that in LFP-Al at the initial stage and after 500 cycles, respectively. Proofs revealed that the electrochemical reaction kinetics and lithium ion diffusion rate were dramatically improved while the carbon cloth was taken as the current collector rather than the $\mathrm{Al}$ foil. When the active materials were directly coated on the surface of the carbon cloth through the sol-gel mechanism of gel coating, the $3 \mathrm{D}$ structure formed the multidimensional transmission path for lithium ions and electrons without inactive matter hindrance. The difference was that the typical 2D plate electrode configuration composed of the active materials; conductive additive and binders had to solve the agglomeration problems of active materials.

\section{Conclusions}

In summary, the monodispersed $\mathrm{LiFePO}_{4} @ \mathrm{C}$ core-shell nanostructures anchored on the $3 \mathrm{D}$ carbon cloth have been 


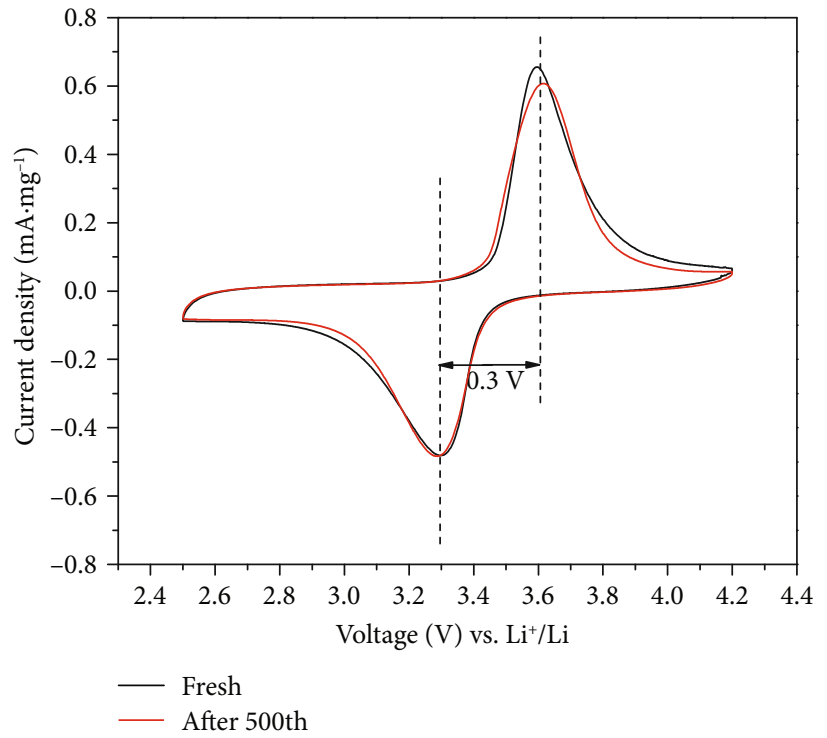

(a)

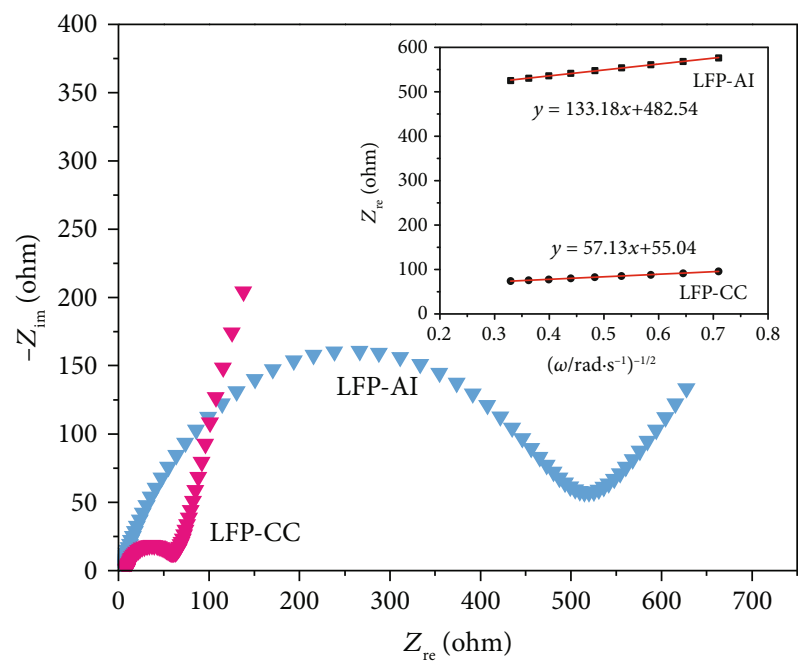

(c)

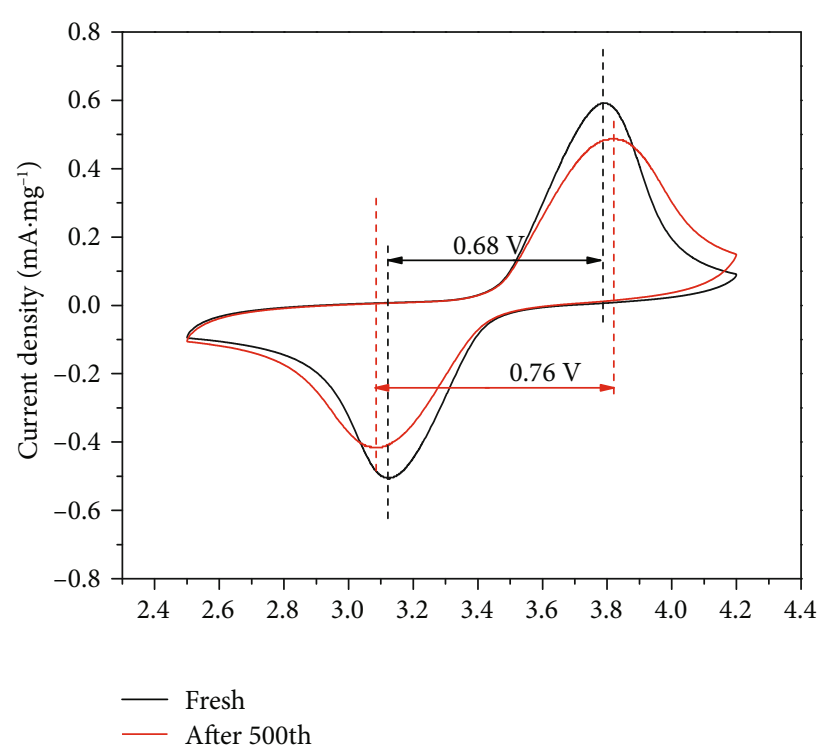

(b)

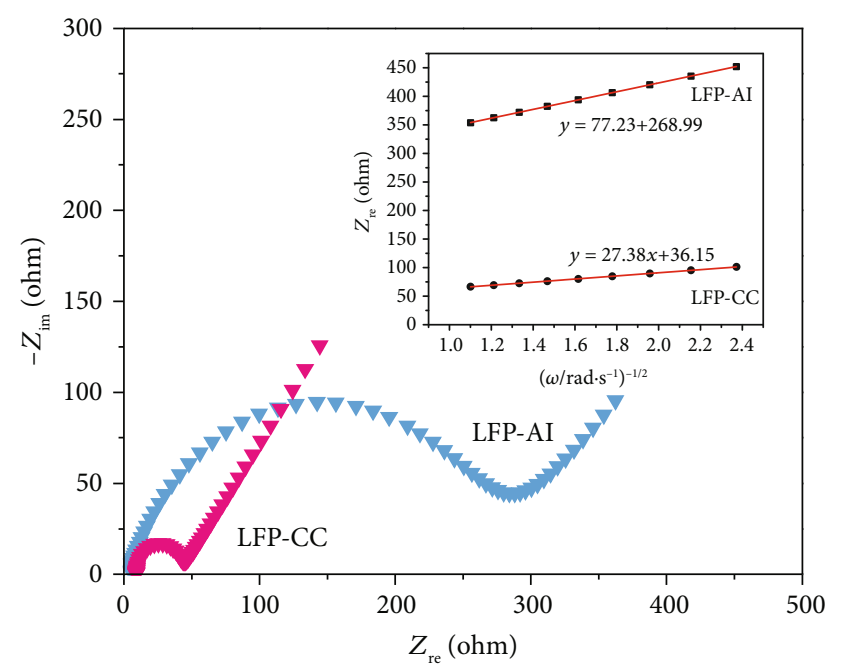

(d)

Figure 7: (a) Cyclic voltammogram curves of LFP-CC. (b) Cyclic voltammogram curves of LFP-Al. (c) Nyquist plots of fresh LFP-Al and LFP-CC and their plots (inset) of impedance as a function of the inverse square root of angular frequency in the Warburg region. (d) Nyquist plots of LFP-Al and LFP-CC after 500 cycles and their plots (inset) of impedance as a function of the inverse square root of angular frequency in the Warburg region.

successfully synthesized through a simple impregnation solgel method. Through the combination of many carbon fibers and well-distributed $\mathrm{LiFePO}_{4}$ with a nanocarbon layer, this $3 \mathrm{D}$ electrode configuration can effectively avoid the conductive additives and polymeric binders. Consequently, the electrolyte can be fully immersed while the active materials hardly fall off from the current collector anchored on the carbon cloth. Compared with the LFP-Al sample, the LFPCC sample shows the remarkably improved specific capacity, rate performance, and capacity retention, especially for large rate performance and long cycle capacity retention. Research findings reveal that $3 \mathrm{D}$ electrode configuration without binders has more potentials than the typical 2D electrode configuration with binders at a large rate and long cycle lifespan. Eventually, our carbon cloth-based composite electrode is seen as a promising cathode material for highrate performance lithium ion battery, providing a brand new pathway of preparing the integral electrode of binderfree system.

\section{Data Availability}

All data included in this study are available upon request by contact with the corresponding author.

\section{Conflicts of Interest}

The authors declare that they have no conflicts of interest. 


\section{Authors' Contributions}

Boqiao Li and Wei Zhao contributed equally to this work.

\section{Acknowledgments}

This research was supported by the Earth Engineering Center and Center for Advanced Materials for Energy and Environment at Columbia University. Support from the National Natural Science Foundation of China (11572238 and 11872302) and Key R\&D Program of Shaanxi (2018ZDXM-GY-131).

\section{References}

[1] J. B. Goodenough and Y. Kim, "Challenges for rechargeable Li batteries," Chemistry of Materials, vol. 22, no. 3, pp. 587-603, 2010.

[2] D. Xie, W. Zhou, K. Lin et al., "Doping effect of fluoride anion on microstructural and electrochemical properties of lithiumrich cathode materials," Materials Letters, vol. 253, pp. 82-85, 2019.

[3] B. L. Ellis, K. T. Lee, and L. F. Nazar, "Positive electrode materials for Li-ion and Li-batteries," Chemistry of Materials, vol. 22, no. 3, pp. 691-714, 2010.

[4] A. K. Padhi, A. K. Padhi, K. S. Nanjundaswamy, and J. B. Goodenough, "Phospho-olivines as positive-electrode materials for rechargeable lithium batteries," Journal of the Electrochemical Society, vol. 144, no. 4, pp. 1188-1194, 1997.

[5] L. X. Yuan, Z. H. Wang, W. X. Zhang et al., "Development and challenges of LiFePO4cathode material for lithium-ion batteries," Energy \& Environmental Science, vol. 4, no. 2, pp. 269-284, 2011.

[6] Q. Liang, H. Yue, S. Wang, S. Yang, K. H. Lam, and X. Hou, "Recycling and crystal regeneration of commercial used $\mathrm{LiFePO}_{4}$ cathode materials," Electrochimica Acta, vol. 330, p. 135323, 2020.

[7] J. Wang and X. Sun, "Understanding and recent development of carbon coating on LiFePO4cathode materials for lithiumion batteries," Energy \& Environmental Science, vol. 5, no. 1, pp. 5163-5185, 2012.

[8] A. S. Aricò, P. Bruce, B. Scrosati, J. M. Tarascon, and W. van Schalkwijk, "Nanostructured materials for advanced energy conversion and storage devices," Nature Materials, vol. 4, no. 5, pp. 366-377, 2005.

[9] F. Croce, A. D’ Epifanio, J. Hassoun, A. Deptula, T. Olczac, and B. Scrosati, "A novel concept for the synthesis of an improved LiFePO[sub 4] lithium battery cathode," Electrochemical and Solid-State Letters, vol. 5, no. 3, pp. A47-A50, 2002.

[10] L. Yang, L. Jiao, Y. Miao, and H. Yuan, "Improvement of electrochemical properties of $\mathrm{LiFePO}_{4} / \mathrm{C}$ cathode materials by chlorine doping," Journal of Solid State Electrochemistry, vol. 13, no. 10, pp. 1541-1544, 2009.

[11] H. H. Chang, C. C. Chang, C. Y. Su, H. C. Wu, M. H. Yang, and N. L. Wu, "Effects of $\mathrm{TiO}_{2}$ coating on high-temperature cycle performance of $\mathrm{LiFePO}_{4}$-based lithium-ion batteries," Journal of Power Sources, vol. 185, no. 1, pp. 466-472, 2008.

[12] H. Liu, G. X. Wang, D. Wexler, J. Z. Wang, and H. K. Liu, "Electrochemical performance of $\mathrm{LiFePO} 4$ cathode material coated with $\mathrm{ZrO} 2$ nanolayer," Electrochemistry Communications, vol. 10, no. 1, pp. 165-169, 2008.
[13] H. Liu, C. Li, H. P. Zhang, L. J. Fu, Y. P. Wu, and H. Q. Wu, "Kinetic study on LiFePO4/C nanocomposites synthesized by solid state technique," Journal of Power Sources, vol. 159, no. 1, pp. 717-720, 2006.

[14] G. Xu, F. Li, Z. Tao et al., "Monodispersed LiFePO4@C core-shell nanostructures for a high power Li-ion battery cathode," Journal of Power Sources, vol. 246, pp. 696-702, 2014.

[15] Y. Chen, K. Xiang, W. Zhou, Y. Zhu, N. Bai, and H. Chen, "LiFePO4/C ultra-thin nano-flakes with ultra-high rate capability and ultra- long cycling life for lithium ion batteries," Journal of Alloys and Compounds, vol. 749, pp. 1063-1070, 2018.

[16] G. Xie, H. J. Zhu, X. M. Liu, and H. Yang, "A core-shell LiFe$\mathrm{PO}_{4} / \mathrm{C}$ nanocomposite prepared via a sol-gel method assisted by citric acid," Journal of Alloys and Compounds, vol. 574, pp. 155-160, 2013.

[17] Y. Yue and H. Liang, "3D current collectors for lithium-ion batteries: a topical review," Small Methods, vol. 2, no. 8, 2018.

[18] G. X. Pan, F. Cao, Y. J. Zhang, and X. H. Xia, "Integrated carbon cloth supported $\mathrm{LiFePO}_{4} / \mathrm{N}-\mathrm{C}$ films as high-performance cathode for lithium ion batteries," Materials Research Bulletin, vol. 98, pp. 70-76, 2018.

[19] K. Moyer, R. Carter, T. Hanken, A. Douglas, L. Oakes, and C. L. Pint, "Electrophoretic deposition of $\mathrm{LiFePO}_{4}$ onto 3-D current collectors for high areal loading battery cathodes," Materials Science and Engineering: B, vol. 241, pp. 42-47, 2019.

[20] G. Zhang, S. Hou, H. Zhang et al., "High-performance and ultra-stable lithium-ion batteries based on MOF-derived $\mathrm{ZnO} @ \mathrm{ZnO}$ quantum dots/C core-shell nanorod arrays on a carbon cloth anode," Advanced Materials, vol. 27, no. 14, pp. 2400-2405, 2015.

[21] K. Saravanan, M. V. Reddy, P. Balaya, H. Gong, B. V. R. Chowdari, and J. J. Vittal, "Storage performance of LiFePO4nanoplates," Journal of Materials Chemistry, vol. 19, no. 5, pp. 605-610, 2009.

[22] R. Muruganantham, M. Sivakumar, and R. Subadevi, "Synthesis and electrochemical characterization of olivine-type lithium iron phosphate cathode materials via different techniques," Ionics, vol. 22, no. 9, pp. 1557-1565, 2016.

[23] L. Castro, R. Dedryvère, M. el Khalifi et al., "The spinpolarized electronic structure of ${ }_{\text {LiFePO4and }}$ FePO4Evidenced by in-lab XPS," Journal of Physical Chemistry C, vol. 114, no. 41, pp. 17995-18000, 2010.

[24] M. S. Bhuvaneswari, N. N. Bramnik, D. Ensling, H. Ehrenberg, and W. Jaegermann, "Synthesis and characterization of Carbon Nano Fiber/LiFePO4 composites for Li- ion batteries," Journal of Power Sources, vol. 180, no. 1, pp. 553-560, 2008.

[25] X. Tu, Y. Zhou, and Y. Song, "Freeze-drying synthesis of threedimensional porous LiFePO4 modified with well-dispersed nitrogen-doped carbon nanotubes for high-performance lithium- ion batteries," Applied Surface Science, vol. 400, pp. 329-338, 2017.

[26] J. Yu, J. Hu, and J. Li, "One-pot synthesis and electrochemical reactivity of carbon coated $\mathrm{LiFePO}_{4}$ spindles," Applied Surface Science, vol. 263, pp. 277-283, 2012.

[27] W. Xiang, Z. G. Wu, E. H. Wang et al., "Confined synthesis of graphene wrapped $\mathrm{LiMn} 0.5 \mathrm{Fe} 0.5 \mathrm{PO}_{4}$ composite via two step solution phase method as high performance cathode for Liion batteries," Journal of Power Sources, vol. 329, pp. 94-103, 2016. 
[28] K. A. Seid, J. C. Badot, O. Dubrunfaut, S. Levasseur, D. Guyomard, and B. Lestriez, "Multiscale electronic transport mechanism and true conductivities in amorphous carbonLiFePO4nanocomposites," Journal of Materials Chemistry, vol. 22, no. 6, pp. 2641-2649, 2012.

[29] M. Rybachuk and J. M. Bell, "The effect of sp2 fraction and bonding disorder on micro-mechanical and electronic properties of a-C:H films," Thin Solid Films, vol. 515, no. 20-21, pp. 7855-7860, 2007.

[30] A. Fedorková, R. Oriňáková, A. Oriňák et al., "Electrochemical and XPS study of LiFePO4 cathode nanocomposite with PPy/PEG conductive network," Solid State Sciences, vol. 14, no. 8, pp. 1238-1243, 2012.

[31] M. M. Doeff, Y. Hu, F. McLarnon, and R. Kostecki, "Effect of surface Carbon Structure on the electrochemical performance of LiFePO[sub 4]," Electrochemical and Solid-State Letters, vol. 6, no. 10, pp. A207-A209, 2003.

[32] A. A. Salah, A. Mauger, K. Zaghib et al., "Reduction ${ }^{\text {Fe[sup } 3+]}$ of Impurities in ${ }_{\mathrm{LiFePO} \text { sub 4] }}$ from Pyrolysis of Organic Precursor Used for Carbon Deposition," Journal of the Electrochemical Society, vol. 153, no. 9, pp. A1692-A1701, 2006.

[33] Y. Zhou, J. Wang, Y. Hu, R. O’Hayre, and Z. Shao, “A porous $\mathrm{LiFePO}_{4}$ and carbon nanotube composite," Chemical Communications, vol. 46, no. 38, pp. 7151-7153, 2010.

[34] J. Li, L. Zhang, L. Zhang et al., "In-situ growth of graphene decorations for high-performance $\mathrm{LiFePO}_{4}$ cathode through solid-state reaction," Journal of Power Sources, vol. 249, pp. 311-319, 2014.

[35] S. C. Nagpure, B. Bhushan, and S. S. Babu, "Multi-scale characterization studies of aged Li-ion large format cells for improved performance: an overview," Journal of the Electrochemical Society, vol. 160, no. 11, pp. A2111-A2154, 2013.

[36] X. Tian, Y. Zhou, X. Tu, Z. Zhang, and G. du, "Well-dispersed $\mathrm{LiFePO} 4$ nanoparticles anchored on a three-dimensional graphene aerogel as high-performance positive electrode materials for lithium-ion batteries," Journal of Power Sources, vol. 340, pp. 40-50, 2017.

[37] K. Zhang, J. T. Lee, P. Li et al., "Conformal coating strategy comprising $\mathrm{N}$-doped carbon and conventional graphene for achieving ultrahigh power and cyclability of $\mathrm{LiFePO}_{4}$," Nano Letters, vol. 15, no. 10, pp. 6756-6763, 2015.

[38] Y. Cui, X. Zhao, and R. Guo, "Improved electrochemical performance of $\mathrm{La}_{0.7} \mathrm{SrO}_{3} \mathrm{MnO}_{3}$ and carbon co-coated $\mathrm{LiFePO}_{4}$ synthesized by freeze-drying process," Electrochimica Acta, vol. 55, no. 3, pp. 922-926, 2010. 